\title{
SEQUÊNCIA DIDÁTICA SOBRE QUALIDADE DO AR: POSSIBILIDADES PARA O ENSINO DE QUÍMICA CONTEXTUALIZADO
}

\section{DIDACTIC SEQUENCE ON AIR QUALITY: POSSIBILITIES FOR CONTEXTUALIZED CHEMISTRY TEACHING}

\section{SECUENCIA DIDÁCTICA SOBRE LA CALIDAD DEL AIRE: POSIBILIDADES PARA LA ENSEÑANZA CONTEXTUALIZADA DE LA QUÍMICA}

\author{
José Francisco Zavaglia Marques ${ }^{1}$ \\ Keiciane Canabarro Drehmer Marques ${ }^{2}$ \\ Vantoir Roberto Brancher ${ }^{3}$
}

\begin{abstract}
Resumo: As ações antropogênicas têm alterado a qualidade do ar, solo, água, flora e fauna e o ensino deve, quando possível, explorar os temas promovendo reflexões sobre esses com os estudantes, para que possam exercer as tomadas de decisões de forma consciente. Este trabalho apresenta uma Sequência Didática (SD) acerca da temática qualidade do ar no município de Cachoeira do Sul-RS. Com o desenvolvimento da SD, buscamos articular os conceitos da disciplina de Química estudados no $1^{\circ}$ ano do Ensino Médio. Dentre as atividades, foi proposto uma situaçãoproblema sobre como está a qualidade do ar do município. Os estudantes realizaram pesquisas para auxiliar na resolução do problema, produzindo relatórios com as respostas. Entre os dados analisados nos relatórios, obtivemos informações por meio de entrevistas com pessoas da comunidade que descreveram o ar da cidade como de boa qualidade. As pesquisas em artigos, sites e documentos governamentais também forneceram dados aos estudantes, corroborando, assim, com a argumentação sobre a possível boa qualidade do ar.
\end{abstract}

Palavras-chave: Ensino de Química. Qualidade do ar. Sequência Didática.

Abstract: Anthropogenic actions have altered the quality of air, soil, water, flora and fauna and teaching should explore themes promoting students' reflections whenever possible, so that they can exercise conscious decision-making. This work presents a Didactic Sequence about the theme of air quality in the city of Cachoeira do Sul-RS. With the development of the didactic sequence, we seek to articulate the concepts of the Chemistry discipline studied in the 1st year of High School. Among the activities, we proposed a problem situation to know how the air quality of the

\footnotetext{
${ }^{1}$ Universidade Federal de Santa Maria. Santa Maria, Rio Grande do Sul, Brasil.

${ }^{2}$ Universidade Federal de Santa Maria. Santa Maria, Rio Grande do Sul, Brasil.

${ }^{3}$ Instituto Federal Farroupilha - Campus Jaguari. Jaguari, Rio Grande do Sul, Brasil.
} 
municipality is. The students did research to help solve the problem, producing reports with the answers. Among the data analyzed in the reports, we obtained information through interviews with people in the community who described the air of the city as being of good quality. Research on articles, websites and government documents also provided data to students, thus corroborating the argument about possible good air quality.

Keywords: Chemistry teaching. Air quality. Didactic Sequence.

Resumen: Las acciones antropogénicas han alterado la calidad del aire, el suelo, el agua, la flora y la fauna y la enseñanza debe, siempre que sea posible, explorar temas que promuevan reflexiones de los estudiantes, para que puedan ejercer una toma de decisiones consciente. Este trabajo presenta una secuencia didáctica sobre el tema de la calidad del aire en la ciudad de Cachoeira do Sul-RS. Con el desarrollo de la secuencia didáctica, buscamos articular los conceptos de la disciplina de la Química estudiados en el primer año de la escuela secundaria. Entre las actividades, se propuso una situación problemática sobre cómo es la calidad del aire del municipio. Los estudiantes llevaron a cabo investigaciones para resolver el problema, produciendo informes con las respuestas. Entre los datos analizados en los informes, obtuvimos información a través de entrevistas con personas de la comunidad que describieron el aire de la ciudad como de buena calidad. La investigación de artículos, sitios web y documentos gubernamentales también proporcionó datos a los estudiantes, corroborando así el argumento sobre la posible buena calidad del aire.

Palabras clave: Enseñanza de la Química. Calidad del aire. Secuencia Didáctica.

\section{INTRODUÇÃO}

O desafio no ensino é despertar o interesse e a motivação dos estudantes para aprender diante das mudanças culturais, sociais e tecnológicas que estamos vivenciando. Antes a escola era reconhecida como a detentora das informações e dos conhecimentos, e agora precisam modificar para continuar ajudando a sociedade nas questões sociais e profissionais relacionadas à aprendizagem.

Os documentos nacionais, como a Lei de Diretrizes e Bases da Educação Nacional, reforçam que a educação tem como finalidade aprimorar nos estudantes o pensamento crítico com potencial de tomar decisões para modificar as situações encontradas em suas realidades locais e globais (BRASIL, 1996). Para isso, as atividades de ensino devem trazer temas contextualizados e articulação das disciplinas com outros conhecimentos para dar sentido e significado aos discentes e relevância da alfabetização científica para os jovens do nosso país.

Uma visão integrada das questões relacionadas à política, ao social e ao ambiental é desejável no ensino, muitas vezes estudados de forma fragmentada, os quais podem ser estabelecidos pela prática da educação ambiental envolvendo todas as disciplinas escolares. Um 
caminho possível, segundo Gadotti e Guitérrez (2005), são práticas de cidadania dentro de um lugar determinado como a escola, uma esquina, um restaurante, uma praça, entre outros. Isto pode trazer bons resultados na formação do sujeito, para que depois esse possa agir em outros espaços do planeta com uma visão integrada da realidade a qual está inserido. Nesse sentido, o cotidiano escolar pode se revelar num dos lugares ímpares para o seu desenvolvimento.

A contextualização do ensino permite aproximar os estudantes dos conteúdos específicos, pois estão inseridos dentro da realidade dos estudantes, trazendo sentido e significados aos conceitos trabalhados. O ensino de Química carece dessa aproximação da vida dos estudantes com os conteúdos, conforme apontado pelo Parâmetros Curriculares Nacionais (PCN), "pesquisa recente com jovens de Ensino Médio revelou que estes não veem nenhuma relação da Química com suas vidas nem com a sociedade" (BRASIL, 2000, p. 79).

Este trabalho demonstra uma abordagem do assunto sobre a qualidade do ar com o uso de problematização dentro de uma Sequência Didática (SD), buscando promover o ensino contextualizado e, assim, auxiliar no desenvolvimento da cidadania ${ }^{1}$ do sujeito, realizando reflexões sobre a qualidade do ar no Município de Cachoeiro do Sul-RS. É neste município que os sujeitos desta pesquisa vivem, almeja-se, portanto, com esta SD estabelecer a contextualização do ensino de Química com os conteúdos conceituais presentes na disciplina de Química do $1^{\circ}$ ano do Ensino Médio.

\subsection{A COMUNIDADE E A EDUCAÇÃO AMBIENTAL}

Segundo a Orientação Nacional nas Diretrizes Curriculares Nacionais para Educação Ambiental DCNEA (2012), o espaço escolar e a comunidade devem promover ações de sustentabilidade socioambientais como foco na prevenção, proteção e preservação do meio ambiente e da saúde humana, tanto no Ensino Básico quanto no Ensino Superior. A inserção da Educação Ambiental deve ser em todas as disciplinas, níveis e modalidades de ensino, apesar de muitas vezes ser explícito nas disciplinas de ciências e biologia, precisamos buscar estabelecer relações entre os assuntos específicos trabalhados com o impacto ambiental e social que está relacionado ao assunto.

\footnotetext{
${ }^{1}$ Definição: cidadania - "significa a realização democrática de uma sociedade, compartilhada por todos os indivíduos ao ponto de garantir a todos o acesso ao espaço público e condições de sobrevivência digna, tendo como valor-fonte a plenitude da vida" (CORRÊA, 1999, p. 217).
} 
Espera-se que um sistema de ensino busque desenvolver nos estudantes uma educação cidadã, responsável, crítica, participativa e emancipatória fortalecendo a tomada de decisões no contexto em que estão inseridos. O exercício do pensamento complexo deve buscar ir além de uma visão linear entre a ação e o objeto, como se fosse em um sentido único nas questões ambientais visando a uma visão integrada e sistemática com suas diversas influências. Esse pensamento, segundo Morin (1999), consiste em evitar a especialização, que acaba abstraindo o objeto do seu contexto, para um estudo no modo de disciplina específicas do currículo, tornando assim uma visão mais contextualizada e ampla da influência que o objeto tem com diversos setores da sociedade.

Segundo a Lei $\mathrm{n}^{\circ} 9.795$ de 1999, a Educação Ambiental é o componente essencial e permanente na educação brasileira, de forma articuladas aos níveis do Ensino Básico e Superior e em suas diversas modalidades. Conforme o DCNEA e a Lei $n^{\circ}$ 9.795/1999, não existem definições para criação de disciplinas ou componentes curriculares específicos que devam abranger a prática da Educação Ambiental. Muitas vezes, essa acaba sendo direcionada para as disciplinas de Ciências e Biologia (BRASIL, 1999, 2012). E a sua prática deve ser integrada, contínua e permanente perpassando todos os níveis e modalidades.

As instituições de ensino devem buscar parcerias e diálogos com a comunidade, produzindo conhecimentos sobre as circunstâncias em que se encontram e soluções socioambientais locais e regionais em busca de condições adequadas de vida. Esse cenário, já mencionado por Gadotti e Guitérrez (2005), de estabelecer parcerias e articulações com a comunidade, orientando a educação a exercer a cidadania e a qualidade de vida, enquadram-se numa educação comunitária. Os autores supracitados afirmam que "a educação comunitária procura demonstrar a integração do local com o nacional e o transnacional. Não posso ser cidadão do mundo sem ser, antes de mais nada, cidadão de um lugar bem determinado" (GADOTTI; GUITÉRREZ, 2005, p. 16).

A ideia anterior reforça o quanto é preciso exercer ações de cidadania dentro dos espaços em que atuamos, tais como no hospital, na escola, na comunidade, nas ruas, entre outros locais. Diante disso, a Lei de Diretrizes e Bases da Educação Nacional (BRASIL, 1996) no Artigo 20 e a Constituição Federal (BRASIL, 1988) no Artigo 205ㅇdestacam que a educação é um dever do estado e da família para o preparo para a cidadania. Cabe ao estado exercer sua função com a educação escolar organizado e orientado pelas Diretrizes e Parâmetros Curriculares Nacionais.

A escola que mantém vínculo forte e permanente com a comunidade tem mais chances de êxito na formação dos estudantes do que aquelas que buscam as soluções sozinhas (GADOTTI; GUITÉRREZ, 2005). Os estabelecimentos de ensino juntamente com os docentes deverão buscar 
articulações com a família e a comunidade, promovendo processos de integração da sociedade com a escola (BRASIL, 1996).

O painel do planeta tem demonstrado que a partir da era industrial os valores humanos sobre a visão da natureza construíram-se de poder de controle. Os bens materiais ganharam grande valorização e, por consequência, vem aumentando o distanciamento com a natureza. O ser humano está trocando a energia viva, dos seres vivos, por energias mecânicas, tornando-se dependentes das máquinas. Esse modelo de comportamento, valores, atitudes, ainda que possa mudar de uma cultura para outra, tem resultado único para todos, com as consequências no meio ambiente (MANSOLDO, 2012).

As diferentes pesquisas realizadas sobre ar, água e solo identificam a poluição e a contaminação dos mesmos. Como exemplo, os autores Souza e Gastaldini (2014) identificam alguns trechos poluídos ou contaminados pelas ações antrópicas no Rio Vacacaí-Mirim, no município de Santa Maria no estado do Rio Grande do Sul. Da mesma forma, Pereira, Cruz e Guimarães (2019) descrevem os impactos no ecossistema com o rompimento da barragem de rejeitos de Brumadinho. Essas ações modificam nossa natureza e contabilizam grandes perdas do ecossistema. Os países, tanto os desenvolvidos quanto os em desenvolvimento, avançam buscando crescimento econômico, muitas vezes, sem medir o preço da dívida que está sendo feita com a natureza.

Dentro da situação apresentada, o trabalho docente não pode ser um mero expositor de conteúdo a partir dos livros, copiando e reproduzindo, com a utilização de listas de exercícios no ensino para repetir uma determinada técnica. É preciso criar, refletir, pensar em um projeto educativo que envolva a comunidade e a escola na intenção de cumprir o seu papel social com um ensino contextualizado e interdisciplinar para que os estudantes percebam que uma extração de mineral, por exemplo, gera impacto social, econômico e ambiental em nível local e global. $\mathrm{O}$ caminho pela educação é uma oportunidade de criar a cidadania dos estudantes com valores, atitudes e comportamentos de reconhecer a Terra como única comunidade (MANSOLDO, 2012, p. 26).

A educação é um recurso que a sociedade criou para desenvolver a formação do sujeito, do seu senso crítico com as questões sociais e ambientais. É importante evidenciar o cuidado que deve se ter com o caminho e a qualidade do ensino realizado, refletindo valores e comportamentos dos sujeitos com o nosso Planeta. Precisamos fortalecer e ampliar nossas ações nos espaços escolares, diante de todas as dificuldades apresentadas pelo sistema educacional em nosso país, com um perfil de estudantes heterogêneos pertencentes a diferentes classes sociais, culturais e econômicas, no 
entanto, os valores e comportamentos devem ser os mesmos em se tratando de preservação do nosso ambiente.

Almejando contribuir com as questões ambientais locais, o trabalho é uma reflexão crítica aos cuidados com a comunidade e à proteção do meio ambiente, buscando mudanças de atitudes que beneficiem a sociedade. É um convite para os estudantes pensarem sobre o equilíbrio e o respeito entre o homem e a natureza, pois os recursos naturais são finitos e as consequências do desequilíbrio estão no nosso passado, no presente e previstos para o futuro das gerações.

A Química inserida dentro da comunidade tem o papel de desenvolver a alfabetização científica, como uma forma de ver o mundo, de compreender e de usar os conhecimentos científicos e, assim, formar um sujeito capaz de tomar decisões. A contextualização traz uma aprendizagem com mais sentido aos estudantes. Quando os estudantes conseguem perceber a aplicabilidade do que foi aprendido, essa aprendizagem é duradoura e permite uma dotação de sentido também para aqueles que não pretendem frequentar um curso na área. A Química da atmosfera está presente nas orientações educacionais nos Parâmetros Curriculares Nacionais Mais ( $\mathrm{PCN}+$ ) da Ciências da Natureza e Matemática, como sugestão de prática e também na articulação da contextualização e interdisciplinaridade dentro da área do conhecimento (BRASIL, 2006).

\subsection{A QUÍMICA DA ATMOSFERA}

O ser humano tem contribuído cada vez mais para a modificação da atmosfera terrestre, isso se potencializou drasticamente a partir da revolução industrial. A camada da troposfera ${ }^{2}$ é o principal alvo de estudo por estar em contato direto com a litosfera e a hidrosfera ${ }^{3}$, pois é o habitat dos seres vivos, local onde ocorrem as interferências dos poluentes. Essa camada é composta pela atmosfera contendo em maior porção substâncias gasosas, existindo partículas sólidas dispersas como microrganismos, poeira, pólen, entre outros, e da própria água a partir da condensação da chuva, neblina e vapor d'água (ROCHA; ROSA; CARDOSO, 2009).

A definição para poluição atmosférica, segundo Nowacki e Rangel (2014), é a adição de substâncias prejudiciais para atmosfera causando danos ao meio ambiente, à saúde e à qualidade de vida. Conforme Derisio (2017) descreve, a poluição é resultado do uso indiscriminado ou abusivo

\footnotetext{
${ }^{2}$ Troposfera camada mais baixa da atmosfera que apresenta uma diminuição constante de temperatura com o aumento da altitude e contém virtualmente toda poeira atmosférica e vapor de água (PETERSEN; SACK; GABLER, 2014).

${ }^{3}$ Hidrosfera subsistema principal da Terra, consiste nas águas, incluindo oceanos, gelo, corpos de água doce, água subterrânea, água no interior da atmosfera e biomassas (PETERSEN; SACK; GABLER, 2014).
} 
das áreas geográficas como limitadas ou confinadas, recebendo e transportando os resíduos gerados do transporte, da combustão, da indústria, da comunicação, entre outros, que são formados pelas ações desenvolvidas pelo homem. Então, a poluição do ar caracterizada pelo lançamento destas substâncias em concentrações suficientes para interferir na qualidade de vida, na segurança, bem-estar ou no pleno uso e gozo de sua propriedade. "Os danos ou efeito da poluição do ar podem ser considerados levando-se em conta alguns aspectos principais, como: saúde, materiais, propriedades da atmosfera, vegetação e economia" (DERISIO, 2017, p. 116).

Os malefícios da poluição do ar à saúde são preocupantes. O relatório da Organização Mundial de Saúde (OMS) emitido em 2018, intitulado "Air pollution and child health: prescribing clean air", aponta os prejuízos da poluição em crianças. Dentre os inúmeros resultados publicados acerca dos malefícios da poluição em crianças, destacamos: prejuízo no neurodesenvolvimento mental e motor, mulheres grávidas expostas à poluição tem maiores chances de ter filhos prematuros, menores e com baixo peso, crianças expostas a altos níveis de poluentes apresentam maior propensão de desenvolvimento de doenças crônicas, entre outros prejuízos apontados.

Os gases formados pela combustão têm efeito nas mudanças da atmosfera, tais como a intensificação do efeito estufa, o desgaste da camada de ozônio e a chuva ácida (ROCHA; ROSA; CARDOSO, 2009). Todo combustível fóssil apresenta impurezas "Na combustão incompleta se produz água $\left(\mathrm{H}_{2} \mathrm{O}\right)$ e parte dos átomos de carbono dá origem a monóxido de carbono (CO) ou simplesmente carbono (C), também chamado de fuligem" (SANTOS; MÓL, 2013, p. 197). Além disso, geraram subprodutos devido às impurezas, por exemplo, o dióxido de enxofre $\left(\mathrm{SO}_{2}\right)$ é o subproduto formado na combustão da gasolina ou do diesel em que contém enxofre (S). Esta substância representa risco à saúde humana, pois é um dos agravantes das doenças respiratórias, além disso o dióxido de enxofre pode sofrer reações químicas com água presente no ar, produzindo a chuva ácida que modifica o pH dos solos e águas. Como forma de controlar os riscos das emissões deste gás, assim como de outras substâncias na atmosfera, foram estabelecidos os padrões de qualidade do ar para o seu monitoramento.

\subsubsection{Padrão de qualidade do ar}

Com intenção de elaborar parâmetros de proteção para a sociedade, foram estabelecidos dois padrões de qualidade: os primários e os secundários, segundo a definição dos conceitos na resolução no 3 do Conselho Nacional de Meio Ambiente (CONAMA): 
I - Padrões Primários de Qualidade do Ar são as concentrações de poluentes que, ultrapassadas, poderão afetar a saúde da população. II - Padrões Secundários de Qualidade do Ar são as concentrações de poluentes abaixo das quais se prevê o mínimo efeito adverso sobre o bem-estar da população, assim como o mínimo dano à fauna, à flora, aos materiais e ao meio ambiente em geral. (BRASIL, 1990, p. 342).

Visando à proteção da qualidade de vida e do meio ambiente, são monitorados os limites dos gases presentes no ar. Cada país tem um órgão regulamentador. No Brasil, é realizado pelo CONAMA e os padrões nacionais são estabelecidos pelo Instituto Brasileiro de Meio Ambiente (IBAMA) (NOWACKI; RANGEL, 2014).

A Resolução $n^{\circ} 3$ CONAMA, de 28 de junho de 1990, estabelece os padrões nacionais de qualidade do ar que inclui poluentes, partículas totais em suspensão, partículas inaláveis, fumaça, dióxido de enxofre $\left(\mathrm{SO}_{2}\right)$, dióxido de nitrogênio $\left(\mathrm{NO}_{2}\right)$, monóxido de carbono (CO) e ozônio $\left(\mathrm{O}_{3}\right)$. De acordo, com o quinto artigo da Resolução $n^{\circ} 3$, o monitoramento da qualidade do ar é atribuído aos estados. No estado do Rio Grande do Sul, é realizado pela Fundação Estadual de Proteção Ambiental Henrique Luiz Roessler (BRASIL, 1990; RIO GRANDE DO SUL, 2019).

Silva e Vieira (2017) destacam o descaso do Brasil sobre o levantamento de dados estatísticos em relação aos poluentes na atmosfera. Os pesquisadores supracitados apontam que

o levantamento de dados relativos à qualidade do ar é de extrema importância para subsidiar o estabelecimento de políticas públicas de saúde, novas legislações mais rigorosas no que tange os limites de emissões e a proposição de planos estratégicos de longo prazo visando à manutenção da qualidade do ar em níveis aceitáveis. (SILVA; VIEIRA, 2017, p. 183).

No Brasil, os estados utilizam os índices de qualidade do ar IQAr (Quadro 1) para divulgar à nossa sociedade os resultados do monitoramento. Nos noticiários, é recorrente a citação dos índices relacionados às grandes capitais, onde ocorrem, normalmente, os maiores problemas de poluição atmosférico do país. Ainda em relação a essa situação, vale mencionar que o cuidado com a qualidade do ar é dever de todos e não apenas do poder público. O poder público é incumbido de monitorar a qualidade do ar, repassar os dados à população e prever medidas de melhorias na qualidade e na redução de emissões de poluentes. 


\subsection{2 Índice de qualidade do Ar (IQAr)}

O Índice de qualidade do $\operatorname{Ar}$ (IQAr) apresenta como principal objetivo proporcionar à população o entendimento e a divulgação da qualidade do ar por meio de informações de seu boletim. Essa ferramenta transforma as concentrações medidas dos diversos poluentes citados em um valor adimensional comparado ao limite permitido. O relatório é divulgado, de acordo com o índice do Quadro 1, que representa as seis classificações da qualidade do ar, relacionando os índices e os níveis de cautela sobre a saúde.

Quadro 1- Índice da qualidade do ar

\begin{tabular}{|c|c|c|c|c|c|c|c|c|}
\hline \multicolumn{9}{|c|}{ ÍNDICE DA QUALIDADE DO AR (IQAr) } \\
\hline Qualidade & índice & $\begin{array}{l}\text { Níveis de Cautela } \\
\text { sobre a Saúde }\end{array}$ & $\begin{array}{c}\mathrm{PI} 2,5 \\
\left(\mu \mathrm{g} / \mathrm{m}^{3}\right)\end{array}$ & $\begin{array}{c}\mathrm{PI} 10 \\
\left(\mu \mathrm{g} / \mathrm{m}^{3}\right)\end{array}$ & $\begin{array}{c}\mathrm{SO}_{2} \\
\left(\mu \mathrm{g} / \mathrm{m}^{3}\right)\end{array}$ & $\begin{array}{c}\mathrm{NO}_{2} \\
\left(\mu \mathrm{g} / \mathrm{m}^{3}\right)\end{array}$ & $\begin{array}{c}\mathrm{CO} \\
(\mathrm{ppm})\end{array}$ & $\begin{array}{c}\mathrm{O}_{3} \\
\left(\mu \mathrm{g} / \mathrm{m}^{3}\right)\end{array}$ \\
\hline Boa & $0-40$ & Seguro à Saúde & $0-25$ & $0-50$ & $0-20$ & $0-200$ & $0-9,0$ & $0-100$ \\
\hline Regular & $41-100$ & Tolerável & $26-20$ & $51-120$ & $21-125$ & $201-260$ & $* * * *$ & $101-140$ \\
\hline Inadequada & 101-199 & $\begin{array}{l}\text { Insalubre para } \\
\text { Grupos Sensíveis }\end{array}$ & 61-124 & $121-249$ & $126-799$ & $261-1129$ & $9,1-14,9$ & 141-199 \\
\hline Má & $200-299$ & $\begin{array}{c}\text { Muito Insalubre } \\
\text { (nível de Atenção) }\end{array}$ & $125-209$ & $250-419$ & $800-1599$ & $1130-2259$ & $15,0-29,9$ & $200-399$ \\
\hline Péssima & $300-399$ & $\begin{array}{c}\text { Perigoso } \\
\text { (nível de alerta) }\end{array}$ & $210-249$ & $420-499$ & $1600-2099$ & $2260-2999$ & $30,0-39,9$ & $400-599$ \\
\hline & $\begin{array}{l}400 \text { ou } \\
\text { maior }\end{array}$ & $\begin{array}{l}\text { Muito Perigoso } \\
\text { (nível de } \\
\text { Emergência) }\end{array}$ & $\geq 250$ & $\geq 500$ & $\geq 2100$ & $\geq 3000$ & $\geq 40$ & $\geq 600$ \\
\hline
\end{tabular}

Os níveis com classificação BOA ou REGULAR, atendem aos Padrões de Qualidade do Ar da Resolução CONAMA 491 de 19/11/2018.

Fonte: adaptado de http://www.fepam.rs.gov.br/qualidade/iqar pop.htm

A partir da identificação da qualidade do ar, são emitidos os alertas pelo governo através dos meios de comunicação para a sociedade, sobre os riscos para saúde e os devidos cuidados que devem ser realizados durante o período. Após uma breve revisão sobre a qualidade do ar, os seus parâmetros e a presença da química da atmosfera, apresentamos o município, no qual foi realizada a atividade teórica e prática. A elaboração e implementação da SD sobre a qualidade do ar teve a intenção de abordar um ensino contextualizado, buscando promover a cidadania e a reflexão do sujeito sobre o meio em que está inserido.

\subsection{CARACTERIZAÇÃO DO MUNICÍPIO DE CACHOEIRA DO SUL}

O município está localizado no centro do estado do Rio Grande do Sul, à margem esquerda do Rio Jacuí e apresenta como principal fator econômico a agricultura e a pecuária, sendo a nona 
maior cidade em território no estado. De acordo com o censo de 2010 do Instituto Brasileiro de Geografia e Estatística, a cidade conta com uma população de 83.827 pessoas, com um índice de desenvolvimento humano municipal (IDHM) 0,742, com saneamento adequado em 35,8\% e arborização em vias públicas de 89,8\% (IBGE, 2019).

Em relação a veículos cadastrados, os dados do Departamento de Trânsito do Estado do Rio Grande do Sul (DETRANRS) apresentam registrado uma frota em circulação na cidade de 27.115 veículos no ano de 2007 e subiu para 49.382 em 2018, uma crescente de 54,9\% e quando comparamos relação habitantes por veículos é cerca de 1,7 pessoas.

A cidade de Cachoeira do Sul é uma microrregião pertencente à mesorregião Centro Oriental Rio-Grandense, composta por outros sete municípios. Dentre os municípios da microrregião, a cidade de Cachoeira do Sul representa a maior população e o maior índice poluidor, porém quando comparamos com a capital do estado do Rio Grande do Sul, a cidade de Porto Alegre que apresenta índice de 4,6679 deste potencial, apenas 8,7\% representaria o município de Cachoeira do Sul (FUNDAÇÃO DE ECONOMIA E ESTATÍ́STICA FEE, 2019). Vale ressaltar que não há barreiras para os poluentes, uma vez que a poluição não fica restrita ao local em que a liberou, causando malefícios à saúde em outras localidades. Informações liberadas pela OSM apresentam que $92 \%$ da população mundial residem em locais em que os níveis da qualidade do ar excedem os limites previstos pela OMS. Outro resultado divulgado é que aproximadamente três milhões de mortes anuais estão relacionadas à poluição atmosférica, sendo $90 \%$ em países de baixa e média renda (OPAS/OMS, 2016).

Neste trabalho, relataremos a implementação de uma Sequência Didática com a temática referente à qualidade do ar do Município de Cachoeira do Sul-RS, na disciplina de Química. Os Parâmetros Curriculares Nacionais $(\mathrm{PCN}+)$ incentivam o assunto relativo à química na atmosfera:

Os estudos associados a este tema possibilitam o desenvolvimento de competências como: compreender o comportamento dos gases na atmosfera, bem como seu papel nos ciclos biogeoquímicos e no sistema produtivo; avaliar, julgar e tomar decisões sobre a poluição atmosférica; buscar informações, analisar e interpretar textos e comunicações referentes ao conhecimento científico e tecnológico para compreender problemas relativos à atmosfera. (BRASIL, 2002, p. 100).

Diante da importância da inserção de temas contextualizados ao ensino, o objetivo deste trabalho é abordar a qualidade do ar perpassando pelos conteúdos conceituais do componente curricular de Química, por meio da abordagem de Sequência Didática. Como o público do trabalho 
foram os estudantes do primeiro ano, o fator que orientou a escolha do tema foi a articulação dos conteúdos conceituais do $1^{\circ}$ ano, como funções inorgânicas, reações químicas, ciclobiogeoquímicos ${ }^{4}$ e forças intermoleculares ${ }^{5}$, abordando-os na perspectiva da realidade local dos estudantes. Além disto, as apostilas utilizadas na turma apresentavam a temática pouco evidente, desta forma o docente da disciplina optou por trabalhar com maior aprofundamento do tema dentro dos conteúdos previstos curricularmente. Uma vez que a temática em questão está inerente na qualidade da vida dos seres vivos, faz-se mais que necessária a discussão em relação aos problemas sociais e ambientais.

\section{CAMINHOS METODOLÓGICOS}

Este trabalho utilizou a metodologia de Sequência Didática com a temática de qualidade do ar. Além dos motivos descritos acima, a idealização do tema concretizou-se a partir das reuniões de planejamento pedagógico realizadas com frequência quinzenal, no terceiro trimestre do ano letivo. O docente do componente curricular de Química e autor deste artigo mapeou os conteúdos trabalhados no $1^{\circ}$ ano do Ensino Médio e propôs uma situação-problema para a turma, além de atividades práticas e discussão de levantamento de dados.

O trabalho foi desenvolvido com os discentes do 10 ano do Ensino Médio, as idades dos estudantes variaram entre 14 a 16 anos e a turma era composta por 31 estudantes. As atividades foram implementadas conforme o planejamento de uma Sequência Didática, a qual se entende como "um conjunto de atividades conectadas entre si, e prescinde de um planejamento para delimitação de cada etapa e/ou atividade para trabalhar os conteúdos disciplinares de forma integrada para uma melhor dinâmica no processo ensino-aprendizagem" (OLIVEIRA, 2013, p. 39).

As etapas da SD podem ser visualizadas no Quadro 2. A inserção de uma Situação-Problema (SP) no desenvolvimento da SD foi com o propósito de estabelecer aproximação da realidade com o estudo dos fenômenos da Ciências da Natureza e estimular pesquisas e levantamento de hipóteses. Ao longo do desenvolvimento da SP, o docente elaborou estratégias didáticas visando a

\footnotetext{
4 Definição: ciclobiogeoquímicos - qualquer um dos vários ciclos químicos que envolvem componentes bióticos e abióticos dos ecossistemas (REECE et al., 2015).

${ }^{5}$ Definição: forças intermoleculares - é o tipo de interação que pode ser formada entre duas ou mais moléculas, íons ou átomos, que de outro modo não estariam associadas. São esses tipos de interações que são responsáveis pela manutenção de substâncias formadas por átomos ou moléculas isoladas em suas fases condensadas, no estado sólido ou líquido (OLIVEIRA; JUNIOR; SCHLÜNZEN, 2013).
} 
orientar os estudantes a alcançarem uma possível resolução da situação, ou seja, conseguir obter dados que possibilitaram levantar hipóteses sobre a qualidade do ar de Cachoeira do Sul.

\begin{tabular}{|c|c|c|}
\hline $\begin{array}{c}\text { Etapas da Sequência } \\
\text { Didática }\end{array}$ & Descrição das atividades desenvolvidas & $\begin{array}{c}\text { Duração } \\
\text { (50 min cada } \\
\text { período) }\end{array}$ \\
\hline 1 Aula expositiva & $\begin{array}{c}\text { Estudo do aquecimento global, efeito estufa, } \\
\text { poluição do ar }\end{array}$ & 2 períodos \\
\hline 2 Aula expositiva & $\begin{array}{c}\text { Funções inorgânicas, reações químicas e padrões } \\
\text { de qualidade do ar }\end{array}$ & 4 períodos \\
\hline $\begin{array}{c}\text { 3 Situação-problema e } \\
\text { relatório }\end{array}$ & $\begin{array}{c}\text { Apresentação da situação-problema e } \\
\text { orientações gerais para pesquisas, entrevistas e } \\
\text { construção do relatório }\end{array}$ & 1 período \\
\hline $\begin{array}{c}\text { 4 Apresentação do relatório } \\
\text { Compartilhamento das pesquisas }\end{array}$ & 2 períodos \\
\hline $\begin{array}{c}\text { 5 Atividade experimental } \\
\text { 6 Apresentação do relatório } \\
\text { experimental }\end{array}$ & $\begin{array}{c}\text { Atividade experimental - poluição do ar } \\
\text { Compartilhamento dos resultados experimentais } \\
\text { e entrega do relatório }\end{array}$ & 1 períodos*** \\
\hline
\end{tabular}

Fonte: autores

* Tempo para realização da atividade de quatro semanas

** Duração do experimento: quatro dias

*** Tempo para realização da atividade de duas semanas

Na primeira e na segunda etapas da SD, foram realizadas aulas expositivas abordando a temática do ar e os conceitos da disciplina de Química, respectivamente. Na terceira etapa, foi lançada uma situação-problema aos estudantes do primeiro ano para que, em grupos de até quatro participantes, realizassem pesquisas e levantassem hipóteses sobre a qualidade do ar do município que residiam.

A SP partia da seguinte questão "O município de Cachoeira do Sul tem potencial para ter boa ou má qualidade do ar?" Para construir o relatório desta etapa, além de responder a SP, os estudantes deveriam acrescentar sugestões de práticas experimentais que pudessem auxiliar na determinação da qualidade do ar da cidade, levantar possíveis soluções a fim de melhorar a qualidade do ar, também deveriam ser realizadas entrevistas com pelo menos dois moradores da cidade sobre a opinião em relação à qualidade do ar da cidade de Cachoeira do Sul-RS. Para auxiliar na construção das respostas e na realização de pesquisas sobre a qualidade do ar da cidade, o professor solicitou que no relatório deveria conter duas resposta para SP, uma baseada em leituras e pesquisas científicas e outra baseada na resposta de moradores da cidade de forma empírica. $\mathrm{Na}$ análise das entrevistas, para manter o sigilo dos grupos e das pessoas entrevistadas, foram 
enumerados os grupos de G1 a G7 e os entrevistados E1 e E2, pois cada grupo realizou duas entrevistas.

Na quarta etapa da SD, ocorreu o momento de socialização dos relatórios. Os grupos apresentaram ao restante da turma as pesquisas e respostas obtidas, além de entregar o relatório ao professor, uma vez que essa era uma das formas de avaliação. $\mathrm{Na} 5^{\circ}$ etapa, a atividade realizada foi uma prática experimental que consistiu em pesar papéis filtros de café antes e depois de serem expostos no ambiente. Os papéis foram fixados em três locais diferentes do colégio, dois pontos internos e um local externo, onde permaneceram por quatro dias. Em relação aos pontos de fixação dos papéis, um ficou localizado próximo à porta de entrada da escola, em frente a uma avenida, outro no interior do pátio do colégio e, por fim, no campo de futebol. Assim, realizamos a comparação de massa dos papéis em contato com ar, também determinamos o pH das amostras com papel indicador. Nesta etapa, os estudantes formaram grupos de aproximadamente dez integrantes, cada um dos três grupos ficou responsável por acompanhar, fotografar, pesar os filtros e anotar os dados obtidos, referentes aos três pontos.

Na última etapa da SD, cada grupo da atividade experimental deveria apresentar aos demais colegas os dados obtidos referentes às práticas dos papéis filtros. O compartilhamento dos resultados experimentais entre os três grupos era com viés de gerar discussão sobre os possíveis locais que tinham maior contaminação do ar retido no papel. Os grupos entregaram o relatório referente aos dados obtidos entre os filtros dos três pontos fixados.

\section{RESULTADOS E DISCUSSÕES}

Nos resultados e discussão serão apresentados os dados referentes às etapas 4,5 e 6 . As três etapas iniciais não apresentaram dados obtidos, visto que era o momento de aula expositiva e de explanação da situação-problema e demais orientações metodológicas sobre a Sequência Didática. Os resultados serão apresentados por etapas referentes às pesquisas contidas no relatório, inicialmente das realizadas em artigos, livros, sites e documentos governamentais e, posteriormente, sobre as entrevistas. Por fim, serão apresentados os dados relacionados à atividade experimental. 


\subsection{APRESENTAÇÃO DAS PESQUISAS}

Na quarta etapa da SD, os estudantes elaboraram um relatório impresso com as respostas obtidas e socializaram com os outros grupos da turma, relatando como fizeram a pesquisa e quais foram as considerações finais do grupo. Neste intervalo de pesquisa de aproximadamente quatro semanas, os estudantes apresentaram dificuldades em como realizar de fato a pesquisa, ou seja, como adquirir as informações necessárias e como interpretar e analisar as informações.

Conforme Pozo (1998), um problema e a busca pela solução exigirá dos estudantes um maior desenvolvimento tanto cognitivo como emocional para resolver tal situação se comparados à resolução de uma lista de exercícios, pois muitas vezes os educandos não estão habituados a resolver problemas. Demonstram inicialmente indecisões e buscam transformar as situações problemas em mero exercícios rotineiros.

Resolver problemas requer dos discentes não só o uso de técnicas, mas também as estratégias presentes nos conteúdos procedimentais e atitudinais na promoção da Educação Científica. Os problemas podem ser compostos por uma única solução ou por diversas, com obstáculos a serem superados. Dentre os obstáculos, pode-se destacar a necessidade de criar novos caminhos para resolver ou reorganizar os meios já conhecidos pelo sujeito, e no desenrolar do trabalho faz-se necessário a orientação do docente, auxiliado com os materiais que podem ser usados e as técnicas escolhidas para coleta de dados. Além disso, a solução de problema requer o uso de estratégias e a tomada de decisões sobre o processo de resolução. Estas etapas demandam atenção do orientador, com olhar dedicado aos grupos que apresentam dificuldades em tomar decisões e a dialogar com os demais integrantes, para que juntos consigam alcançar uma solução.

As pesquisas apresentadas nos relatórios dos grupos obtiveram dados de artigos, livros e sites ligados aos órgãos governamentais. Eles elaboraram argumentos, como exemplo de comparação da qualidade do ar de Cachoeira do Sul com outras cidades do Rio Grande do Sul, também utilizaram a análise e a interpretação de gráficos, mapas e pesquisas que foram realizadas no município e que possibilitaram dar embasamento para a resposta sobre a situação da qualidade do ar apresentada.

A seguir, em forma de tópicos, serão apresentados alguns argumentos, levantados pelos estudantes, contidos nos relatórios com intenção de responder a SP.

- Índice de arborização de vias públicas na cidade é de $89,8 \%$, segundo dados do IBGE; 
- Análise da presença de variedade de líquens usando como referência uma pesquisa realizada pela Universidade Luterana do Brasil ULBRA, Campus Cachoeira do Sul (SILVA et al., 2012);

- Análise de mapas do Centro de previsão de Tempo e Estudos Climáticos CPTEC e do IBGE que demonstram a qualidade do ar na região onde está localizado o Município de Cachoeira do Sul. Análises dos mapas indicam que a escala de monóxido de carbono (CO) no município de Cachoeira do Sul enquadra-se dentro da qualidade do ar considerada boa;

- Utilização de um gráfico representando o número de veículos registrados no município, como fonte possível de redução da qualidade do ar no presente e no futuro da cidade (DETRANRS, 2016).

O trabalho não realizou medições dos parâmetros representados no quadro 1, mas para comparação da escala de classificação do ar entre crítica e boa, os argumentos descritos pelos grupos contribuíram na classificação da qualidade do ar em "boa". A pesquisa científica em livros, artigos e sites de fontes oficiais permitiram corroborar com algumas hipóteses levantadas durante as entrevistas realizadas na comunidade. Os dados usados nos artigos e documentos governamentais auxiliaram na sustentação das hipóteses defendidas pelos grupos sobre a qualidade do ar, pois todo o conhecimento científico para ser considerados aceito pela comunidade científica precisa passar por avaliação e julgamento, e posterior divulgação. De acordo com as autoras Sasseron e Carvalho (2011), a atividade permitiu alcançar o desenvolvimento da argumentação dos discentes e docente. As discussões levantaram hipóteses e exigiram dos discentes a utilização de argumentos para dar credibilidade, produzindo assim justificativas das afirmações e consistência para suas explicações referentes ao tema.

Trabalhar com atividades com temas contextualizados como a qualidade do ar dá sentido e significado para os estudantes do porquê estudar e aprender os assuntos ligados a ciências. A promoção a Alfabetização Científica ${ }^{6}$ na formação cidadã dos estudantes, tanto no domínio, como na compreensão sobre a construção dos conhecimentos científicos, nos desdobramentos nas mais diferentes esferas da vida, torna relevante o ensino para todos os estudantes e não só para aqueles que seguirão a carreira científica.

Diferentemente dos argumentos elaborados a partir de fontes científicas como artigos, dissertações e teses, as entrevistas em sua maioria demonstram o conhecimento de senso comum

\footnotetext{
6 Alfabetização Científica: implica conhecimentos da própria língua e envolve conhecimentos produzidos pela humanidade que permite aos indivíduos compreenderem o mundo natural e suas complexidades e ter experiências mais críticas diante de questões do cotidiano (NASCIMENTO; MORAES; MACHADO, 2015).
} 
da população, que caracterizam as experiências da população em necessidades imediatas, sem a realização de questionamentos de sua validade e suas relações de causa e efeito. Esse tipo de conhecimento é muito utilizado com intenção de criar modelos explicativos e teorias sobre os fenômenos em prol de resolver um problema. No entanto, o conhecimento comum contém suas limitações, não apresentando conhecimentos complexos ou relações abstratas para resolver os problemas apresentados no dia a dia (ARAúJO, 2006).

\subsection{ENTREVISTAS REALIZADAS PELOS ESTUDANTES NA COMUNIDADE}

Além das pesquisas de levantamento científico, a quarta etapa da SD também desafiou os estudantes a realizarem entrevistas com pessoas da comunidade local. Foi utilizada a mesma pergunta da Situação Problema, "O município de Cachoeira do Sul tem potencial para ter boa ou má qualidade do ar?", com os entrevistados para avaliar os argumentos e definir uma classificação da qualidade do ar da cidade de Cachoeira do Sul- RS. Por meio de entrevistas, os estudantes foram divididos em sete grupos, entrevistaram duas pessoas cada, totalizando assim, 14 pessoas entrevistadas em sua maioria da comunidade local e um representante externo. Dentre os entrevistados, destacamos que havia: um representante do IBGE, um biólogo, moradores da zona rural, dos bairros, do centro da cidade e um turista.

Os argumentos apresentados nas entrevistas são em sua maioria baseados em conhecimentos empíricos sobre o assunto. Ao realizar a leitura das entrevistas, podemos destacar que somente duas pessoas consideraram o ar da cidade como "ruim", sendo que apenas um desses apresentou argumentos para sua classificação.

A entrevistada E2G2 afirmou que a qualidade do ar da cidade no período da primavera não é boa, pois causa danos a sua saúde, devido à liberação de pólen. Segundo Nowacki e Rangel (2014), a adição dessas substâncias na atmosfera causa danos à saúde e à qualidade de vida, essas características enquadram-se na definição de poluição atmosférica.

Dos 12 entrevistados que classificaram a qualidade do ar como "boa" e apresentaram justificativas como, comparação com o ar das cidades maiores, a presença de arborização urbana, o pequeno número de indústrias na cidade e o fato da pequena quantidade de automóveis no município. As entrevistas G1E2 e G6E1 são apresentadas abaixo como exemplificação da visão de alguns entrevistados. 
Acredito que Cachoeira não é uma cidade poluída, considerando que não exista muitas indústrias e existe várias áreas verdes (G1E2).

Cachoeira do Sul não tem condições de ser uma cidade com uma qualidade de muito ruim, pelo fato de ser bastante arborizada, não ser perto de metrópoles e não ter trânsito tão intenso como nas grandes cidades (G6E1).

A cidade de Cachoeira do Sul não apresenta um perfil de industrialização, além disso há vários pontos arborizados, grande extensão de zona rural, entre outros argumentos que levam à opinião dos moradores que a qualidade do ar é boa no município.

A utilização de situação-problema possibilita que os estudantes possam elaborar suposições e hipóteses sobre fenômenos estudados e compará-las com explicações científicas. Assim como, que possam utilizar os dados obtidos por meio dos experimentos e avaliar os impactos e as consequências imediatas e/ou futuras que as ações do ser humano podem causar no equilíbrio dinâmico do planeta. Espera-se, diante do problema estudado, um posicionamento mais crítico e participativo dos discentes e o desenvolvimento de inovações para soluções locais.

\subsection{ATIVIDADE EXPERIMENTAL}

Na quinta e na sexta etapa da SD, foi realizada uma atividade de cunho experimental para visualizar conceitos teóricos na prática, possibilitando assim argumentação dos dados teóricos levantados pelos grupos para responder à pergunta: O município de Cachoeira do Sul tem potencial para ter boa ou má qualidade do ar? A atividade experimental foi adaptada do site Ciência na $m a \tilde{o} o^{7}$ da Universidade de São Paulo, em que os papéis filtros foram fixados em diferentes pontos do colégio (Figura 1).

Realizamos determinação do $\mathrm{pH}$ com fita indicador de $\mathrm{pH}$ e do peso dos papéis filtros antes e após o contato com ar. Observamos o aumento do $\mathrm{pH}$ de 5 para 6, esta alteração possivelmente pode ter ocorrido devido à deposição das partículas, além disso ocorreu diferenças nos pesos iniciais para os finais.

\footnotetext{
${ }^{7}$ http://www.cienciamao.usp.br/tudo/exibir.php?midia=ema\&cod= 1-27
} 
Figura 1- Pontos de fixação dos filtros no campo de esportes e em frente ao colégio
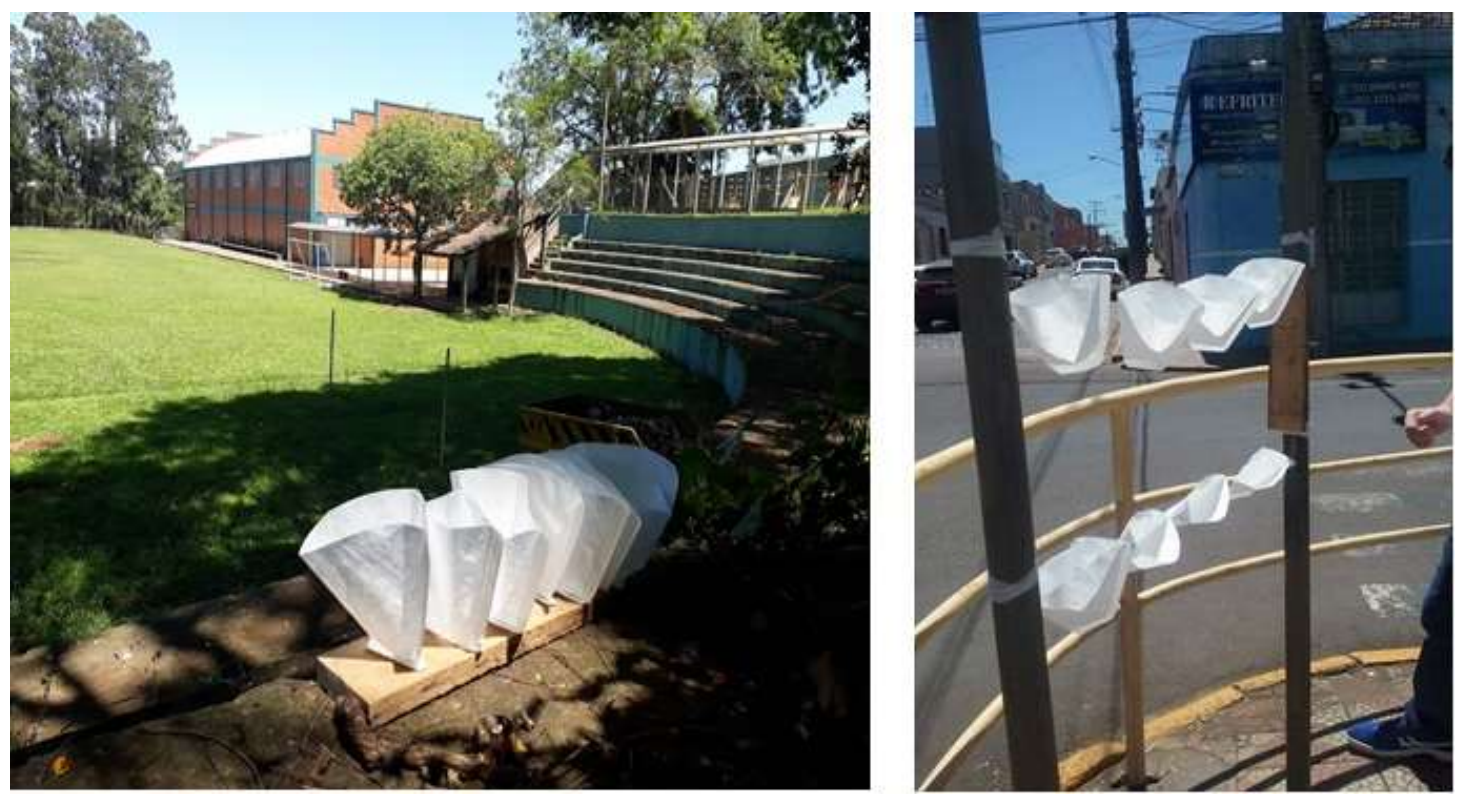

Fonte: autores

Os quadros 3, 4 e 5 representam, respectivamente, os valores da pesagem dos filtros dos pontos fixados próximo ao campo da escola, no pátio e na rua em frente ao colégio, antes e depois do experimento. Lembrando que cada um dos três grupos foi responsável pelo experimento fixado em três pontos do colégio.

Quadro 3- Valores da pesagem dos filtros do campo.

\begin{tabular}{|c|c|c|c|}
\hline Grupos & Valor inicial & Valor final & Diferença \\
\hline Grupo 1 & $1,233 \mathrm{~g}$ & $1,465 \mathrm{~g}$ & $0,232 \mathrm{~g}$ \\
\hline Grupo 2 & $1,314 \mathrm{~g}$ & $1,493 \mathrm{~g}$ & $0,179 \mathrm{~g}$ \\
\hline Grupo 3 & $1,249 \mathrm{~g}$ & $1,485 \mathrm{~g}$ & $0,236 \mathrm{~g}$ \\
\hline
\end{tabular}

Fonte: autores

\begin{tabular}{|c|c|c|c|}
\hline \multicolumn{4}{|c|}{ Quadro 4- Pesagem dos filtros do pátio do colégio. } \\
\hline Grupos & Valor inicial & Valor final & Diferença \\
\hline Grupo 1 & $2,050 \mathrm{~g}$ & $2,268 \mathrm{~g}$ & $0,218 \mathrm{~g}$ \\
\hline Grupo 2 & $1,431 \mathrm{~g}$ & $2,101 \mathrm{~g}$ & $0,67 \mathrm{~g}$ \\
\hline Grupo 3 & $2,204 \mathrm{~g}$ & $2,371 \mathrm{~g}$ & $0,167 \mathrm{~g}$ \\
\hline
\end{tabular}

Fonte: autores

Quadro 5- Pesagem dos filtros da rua em frente ao colégio.

\begin{tabular}{|c|c|c|c|}
\hline Grupos & Valor inicial & Valor final & Diferença \\
\hline Grupo 1 & $2,4 \mathrm{~g}$ & $2,727 \mathrm{~g}$ & $0,327 \mathrm{~g}$ \\
\hline
\end{tabular}




\begin{tabular}{|c|c|c|c|}
\hline Grupo 2 & $2,4 \mathrm{~g}$ & $2,766 \mathrm{~g}$ & $0,366 \mathrm{~g}$ \\
\hline Grupo 3 & $2,2 \mathrm{~g}$ & $2,443 \mathrm{~g}$ & $0,243 \mathrm{~g}$ \\
\hline
\end{tabular}

Fonte: autores

Conforme podemos observar, nos quadros 3, 4 e 5 todos os papéis filtros apresentaram aumento de massa após sua exposição. Quando questionados sobre as hipóteses que justificam o aumento do peso final do papel filtro, os discentes responderam que é devido à absorção do pó vindo do campo, os gases liberados pelos veículos próximos e da presença da umidade do ar.

Os argumentos utilizados nas pesquisas bibliográfica e nas entrevistas realizadas enquadraram a qualidade do ar do município como boa com bases índices de qualidade do ar, já a atividade experimental não apresentou dados e análises de cunho científico para auxiliar na argumentação. O experimento foi uma proposta prática de identificar e avaliar de maneira qualitativa, por meio do registro fotográficos do papel antes e depois, diferença com a pesagem dos valores iniciais e finais, após exposto por quatro dias em pontos distintos. O docente destacou em sala de aula que esse tipo de experimento não é utilizado para quantificar e identificar a presença dos gases poluentes no ar como dióxido de enxofre $\left(\mathrm{SO}_{2}\right)$ e carbono $(\mathrm{C})$ e outros descritos no Quadro 1, no entanto, é uma prática de baixo custo e aplicável na Educação Básica para identificar a quantidade de partículas presente no ar e estabelecer reflexões com os estudantes sobre o tipo e o tamanho das partículas depositados no papel.

A utilização da estratégia de Sequência Didática ocorreu no terceiro trimestre do ano e possibilitou o desenvolvimento de conteúdos conceituais do componente curricular de Química, aliado com a temática da qualidade do ar do município em que os estudantes residiam. Também, as diferentes etapas das atividades proporcionaram além do desenvolvimento conceitual, o procedimental e o atitudinal dos educandos. As pesquisadoras Silva e Quadros (2016) realizaram atividades, com os estudantes do Ensino Médio, com tema e enfoque semelhante ao deste estudo sobre a da qualidade do ar ligada ao ensino de Química. A escolha do tema se deu devido à importância de discutir problemas sociais e ambientais que interferem na qualidade de vida. As autoras supracitadas destacaram que inicialmente os estudantes apresentam dificuldades de relacionar o conhecimento escolar para explicar os fenômenos cotidianos, mas o desenvolvimento do tema favorece discussões sobre os aspectos químicos envolvendo os gases atmosféricos, tais como a camada de ozônio e a chuva ácida. 
A abordagem possibilitou a contextualização da disciplina em questão com a realidade local dos estudantes, fugindo dos exemplos utilizados muitas vezes em materiais didáticos de outros países e cidades que não a retratam. A SD também possibilitou o protagonismo dos discentes como construtores do próprio conhecimento, realizando pesquisas, entrevistas e levantamento de hipóteses para questões em que não há respostas prontas para serem copiadas. Os discentes precisaram ter embasamento, estudos, discussões para conseguirem desenvolver a etapa referente à questão problema que foi lançada sobre a qualidade do ar do município.

Por fim, o fechamento das atividades propostas na SD permitiu a inserção de um estudo mais investigativo, voltado para o desenvolvimento de uma alfabetização científica que tanto espera-se na Educação Básica. Com o incentivo de estudantes protagonistas, críticos, sujeitos ativos no processo de aprendizagem, na tentativa de desconstruir um ensino que ainda implementa práticas memorização e descontextualizadas, buscamos e incentivamos a incorporação de estratégias didáticas que valorizem a autonomia e protagonismo discente, perpassando os conteúdos conceituais das disciplinas envolvidas de modo contextualizado e significativo à realidade dos educandos, distanciando-os dos exemplos fictícios e desconexos da vivência deles.

\section{CONSIDERAÇÕES FINAIS}

A realização do estudo sobre o tema qualidade do ar buscou sensibilizar os estudantes a fim de perceber, analisar e avaliar os impactos que estão acontecendo em nível local e global. Buscamos com a implementação das etapas da Sequência Didática desenvolver nos educandos o senso crítico, argumentativo, assumindo responsabilidade como sujeito inserido na comunidade.

As dificuldades apresentadas no processo de pesquisa e realização dos relatórios mostram que os desafios de interpretar e compreender as informações é um obstáculo muito evidente entre os estudantes, o qual precisa ser trabalhado com auxílio de Educação Científica. O incentivo a atividades de cunho investigativo pode auxiliar os estudantes a utilizarem estratégias e técnicas para resolver problemas, não só dentro do espaço escolar como na vida, possibilitando momentos de reflexão, argumentação e agindo como cidadãos participantes da vida em sociedade.

A promoção da sustentabilidade socioambiental com envolvimento de sujeitos participativos na tomada de decisões requer que o docente vá além de um ensino expositivo com lista de exercícios e memorização desconexas de conceitos. Com o desenvolvimento de um ensino de carácter investigativo, explorando a Alfabetização Científica dos sujeitos aprendentes, lançando 
situações-problemas, provocando levantamento de hipóteses com discussões baseadas em dados científicos, caminhamos para o aperfeiçoamento de sujeitos críticos e participativos

Além disso, a integração de outras disciplinas possibilitou um enriquecimento na estratégia didática de SD. A resolução de situações-problemas, a partir do estabelecimento de parcerias entre os docentes em realizar atividade em grupo com viés interdisciplinar, permitiu um olhar mais complexo e amplo, com diferentes saberes envolvidos.

Somando as hipóteses levantadas pela comunidade, juntamente com os dados das pesquisas, os estudantes chegaram a possível conclusão de que a qualidade do ar em Cachoeira do Sul pode ser considerada boa. O ensino tornou-se participativo por parte dos estudantes, com a inserção de atividades que proporcionaram a análise da situação local e a procura de argumentos científicos que sustentaram e embasaram os dados obtidos, além de propiciar a interlocução das visões do senso comum com as científicas, aproximando as questões da comunidade local em busca de soluções para a qualidade de vida.

A SD implementada possibilitou que os estudantes desenvolvessem a habilidade de interpretações de símbolos, gráficos, tabelas entre outros conceitos estudados no ensino de Química. O tema abordado aproximou-se das finalidades do Ensino Médio, que procura o desenvolvimento pleno do educando, com a formação do senso crítico, relacionando a teoria com a prática, conforme indicam os documentos oficiais. Sendo assim, este estudo buscou apresentar um ensino de Química de forma contextualizada e com maior significado para os estudantes, com viés de abordar a Alfabetização Científica, possibilitando, assim, compreender e interpretar não só os impactos ambientais, mas estabelecer conexões com olhar social, econômico e político causado pela produção de gases na combustão dos combustíveis fósseis em nível local e global, aplicando efetivamente os conhecimentos escolares na vida de cada um.

\section{REFERÊNCIAS}

ARAÚJO, C. A. Á. A ciência como forma de conhecimento. Ciências \& Cognição, Rio de Janeiro, v. 08, n. 1, p. 127-142, 2006. Disponível em:

http://www.cienciasecognicao.org/revista/index.php/cec/article/view/572. Acesso em: 13 dezembro de 2019.

BRASIL. Constituição da República Federativa do Brasil do Brasil. Brasília: Presidência da República Casa Civil, 1988. Disponível em: http://www.planalto.gov.br/ccivil 03/constituicao/constituicao.htm. Acessado em: 27 de dezembro de 2019. 
BRASIL. Lei № 9.394, DE 20 DE DEZEMBRO DE 1996: Estabelece as diretrizes e bases da educação nacional. Brasília: Presidência da República Casa Civil Subchefia Para Assuntos Jurídicos, 1996. Disponível em: http://portal.mec.gov.br/seesp/arquivos/pdf/lei9394_ldbn1.pdf. Acesso em: 27 de fevereiro de 2020.

BRASIL. Lei № 9.795, DE 27 DE ABRIL DE 1999: Dispõe sobre a educação ambiental, institui a Política Nacional de Educação Ambiental e dá outras pr. Brasília, 1999. Disponível em: https://www.camara.leg.br/proposicoesWeb/prop mostrarintegra;jsessionid=50EE32BD99AF52E B7D5DB8E7E03AE765.node1?codteor=634068\&filename=LegislacaoCitada+-PL+4692/2009. Acesso em: 10 de fevereiro de 2020.

BRASIL. Secretaria de Educação Média e Tecnológica. Parâmetros Curriculares Nacionais para o Ensino Médio. Brasília: MEC/SEMTEC, 2000. Disponível em:

http://portal.mec.gov.br/seb/arquivos/pdf/blegais.pdf. Acesso em: 22 de dezembro de 2019.

BRASIL. Secretaria de Educação Média e Tecnológica. PCN+ Ensino Médio: orientações educacionais complementares aos Parâmetros Curriculares Nacionais. Ciências da Natureza, Matemática e suas Tecnologias. Brasília: MEC, SEMTEC, 2002. Disponível em: http://portal.mec.gov.br/seb/arquivos/pdf/CienciasNatureza.pdf. Acesso em 27 de dezembro de 2019.

BRASIL. Orientações Educacionais Complementares aos Parâmetros Curriculares Nacionais. Ciências da Natureza e Matemática e suas tecnologias. Brasília: MEC, 2006. Disponível em: http://portal.mec.gov.br/seb/arquivos/pdf/book volume 02 internet.pdf. Acesso em 22 de dezembro de 2019.

BRASIL. Resolução no 2, DE 15 DE JUNHO DE 2012: Estabelece as Diretrizes Curriculares Nacionais para a Educação Ambiental. Brasília: Ministério da Educação, 2012. Disponível em:

http://portal.mec.gov.br/dmdocuments/rcp002 12.pdf. Acesso em: 22 de dezembro de 2019.

BRASIL. Resolução Conselho Nacional do Meio Ambiente (CONAMA) n 3, 28 de junho de 1990. Dispõe sobre padrões de qualidade do ar, previstos no PRONAR. Brasília, 1990. Disponível em: http://www.ibram.df.gov.br/images/resol 03.pdf. Acesso em 07 de junho de 2020.

CORRÊA, D. A construção da cidadania: reflexões históricas - políticas. ljuí: Ed. UNIJUI, 1999.

DERISIO, J. C. Introdução ao controle de poluição ambiental. 5.ed. São Paulo: Oficina de Textos, 2017.

DETRANRS. Departamento de Trânsito do Rio Grande do Sul. Rio Grande do Sul, 2019.

IBGE. Instituto Brasileiro de Geografia e Estatística. Brasília: Brasil, 2019.

FUNDAÇÃO DE ECONOMIA E ESTATÍSTICA. Indicadores Ambientais. Rio Grande do Sul: Rio Grande do Sul, 2019. 
GADOTTI, M.; GUTIÉRREZ, F. Educação comunitária e economia popular. 4.ed. São Paulo: Cortez, 2005.

MANSOLDO, A. Educação ambiental na perspectiva da ecologia integral: Como educar neste mundo em desequilíbrio? Belo Horizonte: Autêntica Editora, 2012.

MORIN, E. Da necessidade de um pensamento complexo. Paris (FR): UNESCO,1999.

NASCIMENTO, M. S.; MORAES, G. P.; MACHADO, M. A. D. Alfabetização científica e seus desafios no ensino fundamental. In: Anais do XII Congresso Nacional de Educação, Paraná: PUCPR, 2015. 9 p. Disponível em: https://educere.bruc.com.br/arquivo/pdf2015/18615 10275.pdf. Acesso em: 23 março de 2020.

NOWACKI, C. C. B.; RANGEL, M. B. A. Química ambiental: conceitos, processos e estudo dos impactos ao meio ambiente. 1. ed. São Paulo: Érica, 2014.

OLIVEIRA, M. M. Sequência didática interativa no processo de formação de professores. Petrópolis, RJ: Vozes, 2013.

ORGANIZAÇÃO MUNDIAL DA SAÚDE(OMS). Air pollution and child health: prescribing clean air, 2018. Disponível em: https://apps.who.int/iris/bitstream/handle/10665/275545/WHO-CED-PHE-18.01eng.pdf?ua=1. Acesso em: 8 de junho 2020.

ORGANIZAÇÃO PAN-AMERICANA DE SAÚDE/ORGANIZAÇÃO MUNDIAL DE SAÚDE. (OPAS/OMS) OMS divulga estimativas nacionais sobre exposição à poluição do ar e impacto na saúde. 2016. Disponível em:

https://www.paho.org/bra/index.php?option=com content\&view=article\&id=5249:oms-divulgaestimativas-nacionais-sobre-exposicao-a-poluicao-do-ar-e-impacto-na-saude\&ltemid=839. Acesso em: 8 de junho 2020.

OLIVEIRA, O. M. M. F.; JUNIOR, K. S.; SCHLÜNZEN, E. T. M. Química. São Paulo: Cultura Acadêmica: Universidade Estadual Paulista Núcleo de Educação à Distância, 2013.

PEREIRA, L. F.; CRUZ, G. B.; GUIMARÃES, R. M. F. Impactos do rompimento da barragem de rejeitos de Brumadinho, Brasil: uma análise baseada nas mudanças de cobertura da terra. Journal of Environmental Analysis And Progress, Recife, v. 4, n. 2, p. 122-129, 2019. Disponível em: http://www.journals.ufrpe.br/index.php/JEAP/article/view/2373/482483023. Acesso em: 28 de janeiro de 2020.

PETERSEN, J. F.; SACK, D.; GABLER, R. E. Fundamentos de geografia física: Tradução da 1a edição norte-americana Thiago Humberto Nascimento; Cengage Learning, 2014.

POZO, J. I. A solução de problemas: aprender a resolver, resolver para aprender. Porto Alegre: Artmed, 1998.

REECE, J. B.; WASSERMAN, S. A.; URRY, L. A.; CAIN, M. L.; MINORSKY, P. P.; JACKSON, R. B.; CAMPBELL, N. A. Biologia de Campbell. Porto Alegre: Artmed, 2015. 
RIO GRANDE DO SUL. FEPAM. Fundação Estadual de Proteção Ambiental Henrique Luiz Roessler RS. Rio Grande do Sul: Fepam, 2019.

ROCHA, J. C.; ROSA, A. H.; CARDOSO, A. Introdução à química ambiental. 2. ed. - Porto Alegre: Bookman, 2009.

SANTOS, W. L. P.; MÓL, G. S. Química cidadã: volume 2. Ensino médio. 2o série. 2 ed. São Paulo: Editora AJS, 2013.

SASSERON, L. H.; CARVALHO, A. M. P. Investigações em Ensino de Ciências: uma revisão bibliográfica. Investigações em Ensino de Ciências, Porto Alegre, v. 16, n. 1, p.59-77, set. 2011. Disponível em: https://www.if.ufrgs.br/cref/ojs/index.php/ienci/article/view/246/172. Acesso em: 12 de março de 2020.

SILVA, V. R. ; BARRETO, F. S. ; GOLDSCHMIDT JUNIOR, J. L. ; GOLDSCHMIDT, A. I. Uso de liquens para avaliação da qualidade do ar no município de Cachoeira do Sul, RS. In: Anais XV Mostra de Iniciação Científica e V Mostra de Extensão ?Aprender, construir e interagir com o conhecimento na universidade: a articulação ensino, pesquisa e extensão? Cachoeira do Sul, 2012. Disponível em: http://www.conferencias.ulbra.br/index.php/sic/xviii/paper/view/151 . Acesso em 23 de março de 2020.

SILVA, M. A. N.; QUADROS, A. L. Ensino por Temas: A Qualidade do Ar Auxiliando na Construção de Significados em Química. Química Nova na Escola, v. 38, n. 1, p. 40-46, fev. 2016. Disponível em: http://anesc.sbq.org.br/online/qnesc38 1/08-RSA-63-13.pdf. Acesso em 17 de janeiro de 2020.

SILVA, A. F.; Vieira, C. A. Aspectos da poluição atmosférica: uma reflexão sobre a qualidade do ar nas cidades brasileiras. Revista Ciência e Sustentabilidade, v. 3, p. 166-189, jan/jun. 2017. Disponível em:

https://periodicos.ufca.edu.br/ojs/index.php/cienciasustentabilidade/article/view/180/pdf\%20180 Acesso em 9 de junho de 2020.

SOUZA, M. M.; GASTALDINI, M. C. C. Avaliação da qualidade da água em bacias hidrográficas com diferentes impactos antrópicos. Engenharia Sanitária e Ambiental, v. 19, n. 3, p. 263-274, set. 2014. Disponível em: https://www.scielo.br/pdf/esa/v19n3/1413-4152-esa-19-03-00263.pdf. Acesso em 05 de fevereiro de 2020.

\section{SOBRE OS AUTORES}

\section{José Francisco Zavaglia Marques}

Doutorando em Educação em Ciências pelo Programa de Pós-Graduação em Educação em Ciências/ UFSM Universidade Federal de Santa Maria (UFSM); Grupo de Pesquisa- Métodos e Processos de Ensino e Aprendizagem de Ciências (MPEAC).

E-mail: franciscoquimica12@gmail.com

ORCID: https://orcid.org/0000-0002-7866-112X 


\section{Keiciane Canabarro Drehmer Marques}

Doutoranda em Educação em Ciências pelo Programa de Pós-Graduação em Educação em Ciências/ UFSM Universidade Federal de Santa Maria (UFSM); Técnica em laboratório/ biologia- UFSM. Grupo de PesquisaMétodos e Processos de Ensino e Aprendizagem de Ciências (MPEAC).

E-mail: keicibio@gmail.com

ORCID: https://orcid.org/0000-0002-5338-8534

\section{Vantoir Roberto Brancher}

Doutor em Educação pela Universidade Federal de Santa Maria; Professor efetivo do Instituto Federal Farroupilha (IFFar)- Campus Jaguari. Professor Efetivo no Programa de Pós-Graduação em Educação Profissional e Tecnológica do Instituto Federal Farroupilha e Professor Atuante no Programa de PósGraduação em Educação Profissional e Tecnológica da Universidade Federal de Santa Maria; Grupo de Pesquisa MAGMA- Grupo de Estudos e Pesquisas em Formação Inicial e Continuada de Professores.

E-mail: vantoir.brancher@iffarroupilha.edu.br

ORCID : https://orcid.org/0000-0003-2829-7320

Recebido em: 21/05/2020

Aprovado em: $18 / 06 / 2020$

Publicado em: 23/07/2020 